\title{
Gender in "Our Arabic Language" Books for the First Three Grades in Jordan
}

\author{
Khitam Ahmad Bani Omar (Assistant Professor) \\ Curriculum and Teaching, Department of Curriculum, \\ Faculty of Educational Sciences, Jerash University, Jordan
}

Doi: 10.19044/esj.2018.v14n11p59 URL:http://dx.doi.org/10.19044/esj.2018.v14n11p59

\begin{abstract}
This paper focuses on identifying the reality of gender in "our Arabic language" books for the first three grades in Jordan. To achieve the objective of the study, we made use of the descriptive analytical method. Also, we represented the study community in "our Arabic language" books for the first three grades in Jordan. In this study, various tools for analysis have been developed and verified. After the analysis has been verified, the results of the study show that the Committee for the writing of Arabic language books for the first three grades had majority of females. The authoring team and the review team were mostly male. It showed that the total number of repeated gender-related words (males) reached 922 and $70.87 \%$ in total. The gender gap (females) reached $379(29.13 \%)$. The total number of gender-related images (males) was $250(71.43 \%)$ based on the total number of photographs. Gender images (females) reached 100 and $28.57 \%$ of the total number of images. The total number of gender-related addresses (males) reached 8 by $16.67 \%$ of the total number of addresses. The gender-related titles were 2 and $4.17 \%$ of the total number of addresses, and 38 by $79.16 \%$ for the general addresses based on the total number of addresses. The analysis of gender roles showed that the occupations practiced by women are limited to 6 occupations, with the most prominent being a nurse and a teacher. The professions which were related to males are 20 professions, most notably pilot, fisherman, and farmer. It showed that creativity and innovation, health roles, heroism, courage, and ownership of property are limited to males without females. In regards to social roles, males can be seen as father, uncle, brother, grandfather and cousin, while the female can be seen as mother, grandmother, and aunt. The results showed a more male role than female roles.
\end{abstract}

Keywords: Arabic language books, gender, first three basic grades, Jordan 


\section{Introduction}

Developed and developing countries are majorly concerned with education and its development because it is linked to comprehensive development and socialization. Developed countries are developing their educational systems in order to advance their leadership, while developing countries are having the hope of catching up with developed countries.

Consequently, Information Technology revolution has resulted in a knowledge revolution accompanied by a change in many of the prevailing concepts and values in societies. As a result, States are required to make changes that are consistent with this change and that meets with their requirements. Educational institutions is an effective and influential tool in changing concepts and values, replacing new concepts and values, and creating awareness among individuals by preparing them to accept and adapt to new ones (Margaret \& Moris, 1972).

Gender is one of the most widely discussed concepts in national, regional and global political, social, and economic circles. There are indicators that can measure the extent to which countries are committed to its concept. This, however, refers to the roles and responsibilities that society determines for women and men, and how society views them through such responsibilities (Rugby, 2015). These gender roles are defined as the trends and behaviors expected, determined, and defined by society for each race. They include the rights and responsibilities of the two sexes in the society; therefore, they are not fixed over time or between cultures and societies, but they are rather dynamic and changing (Shteiwi \& Dagestani, 1995; UNIFEM, 1999).

Rubin and Barrett (2009) points out that gender is the defining characteristics of society for women and men and it includes economic, social, political and cultural characteristics, as well as the roles and responsibilities of men or women.

Nevertheless, there have been many calls for the promotion of gender equality. This can be defined as ensuring equal participation of women and men in social, economic, and political life. It reflects the concern to provide the same living conditions for women and men in order to refrain from treating them as if they were one person. Gender equality is not only a matter for women, but also for both women and men. It is intended to accept and recognize the differences between women and men and the different roles they play in society (Hashim \& Mansour, 2012).

It is the responsibility of the educational system in any society to bring about the desired changes and to change the roles of individuals in accordance with the developments of cultural, economic, and social life in the society. The school is regarded as the unit that carries out the educational process in a deliberate manner and in accordance to the goals and programs that have been developed and planned in advance. It also contributes in defining the main 
lines of their personalities and characteristics that allows them to form the distinctive image of individuals according to their roles (Al-Spalk, 2004).

Hammoud (2006) indicates that School education plays a key role in the development of the intellectual learners' structures, in imparting values and trends in the society, in establishing them based on their personalities, and in influencing their behavior in all aspects of life. This role comes to school education through the educational curriculum in its broad sense and what it conveys to learners.

The curriculum in its modern concept represents a set of educational experiences set up by the school for students to help them to grow in a comprehensive and integrated manner in various aspects of their personality. The curriculum must play its role as an educational tool that contributes to enhancing the perception of women's status in the society (Apple, 1995). Textbooks are one of the most prominent expressions of the school curriculum and it is an important part of the curriculum. Furthermore, it is important for countries to form and develop specialized teams. This is in addition to the teams that supervise their teams, and the teams that audit them to ensure their quality and exit in the best possible way.

The school plays an essential role in socialization because it is an essential source in instilling the prevailing values in society and in contributing to determining the social role of the individual through the models they provide based on the content of the curricula and textbooks. The importance of the adoption of gender analysis in education, especially in the content of the article and the content of textbooks, has an impact on the ideas and aspirations of generations. The books we adopt in our schools can focus on monitoring the division of the roles between males and females (reproductive role, productive role and political role). These roles, however, are focused on females, males, and the linguistic discourse. As a result, there is a language of the school, which is usually masculine and less neutral, and there are no talking to females, expectations, pictures, and drawings (Hashim \& Mansour, 2012).

A number of studies have dealt with gender in school textbooks. AlAga (2012) pointed to the focus of textbooks' content on the presentation of social and family roles for women. It also shows their religious, historical, and professional roles, rights and issues in addition to not including the content of the books due to the many roles of women, less attention to the political, national and professional roles of contemporary women, and as a result of the lack of focus on women's rights and issues.

Amini and Birandiji (2012) noted that prejudice is still evident in textbooks. This is evidenced by the low rate of women's appearance in texts and drawings, the introduction of male pronouns or pronouns on females in sentences, and the more pronounced bias in professions. In addition, it also 
entails the functions assigned to women in content that revolves around their work in education or nursing.

Yang (2014) showed that both males and females were equally represented based on the content, participation in activities, and the female images which appeared more clearly in the illustrations. This is despite the fact that male names were first mentioned in sentences concerning both sexes. These books have gotten rid of what prevailed in previous books of dominance of the roles of males.

Al-Sarabi (2010) pointed out that the image of the man is independent. Women occupied the specific traditional jobs, while men occupied many major functions, ignoring the literary, scientific, philosophical, and heroic works of women. However, the man's role was evident in these areas. Also, the language was not activated in a gender-neutral and systematic manner.

As for Naji and Rifa'i (2011), their studies showed that women's roles are ranked in a descending order in Arabic language books and social materials as follows: mother, girl, pupil, sister, woman, girl, teacher, Muslim, and nurse. The fields ranked in descending order include: religious and historical, educational, traditional, professional, family, moral in all books of Arabic language, and social materials in the primary and intermediate stages. The social situation was also ranked in a descending order: married, divorced, and widowed.

The study of Jackie and Collins (2010) showed that women are associated with traditional stereotypical roles and are characterized by weaker personality characteristics and more negative personality than men. Kurshid et al. (2010) has shown that women's representation is low, and is attributed to the great and grand work of men which usually appears in images of power and sovereignty. This is unlike women who come in as a subordinate in specific occupations and activities.

\section{The Problem of the Study and its Questions}

The World Economic Forum's “Gender Gap" report of 2014 shows Jordan's declining role of the rank of 119 between 134 countries to the rank of 134 out of 142. This is a disturbing indicator of the reality of women. The report states that Jordan ranked $13^{\text {th }}$, among 16 countries in the Middle East and Africa, behind most of the Arab countries.

Several studies have recommended the study of the subject of gender in the curriculum. Sarabi (2010) pointed to the need to activate the role of the educational system in enhancing the positive image of women and their status in the family and society. It also states their role in social development and their representation in all institutions to eliminate the appearance of gender discrimination. The study of Al-Ma'mory (2009) revealed the necessity of balanced presentation of the image of women through textbooks, and also 
shows a comprehensive review of these curricula in order to evaluate them in light of the roles, rights, and duties of women. Asali (2006) and Jarbawi and Saafin (2004) recommended that women have to be better represented in school textbooks. The study of the Aga (2008) pointed out the need to pay attention to the quality of representation of women and their exclusion from the space of stereotypes; thus, it opines the need to ensure that the curriculum administrators take into account the distribution of professions fairly between men and women in line with the reality of society to some extent.

Due to the social role of the language curriculum, Hammadna and AlMughayd (2011) stated that the language curriculum is one of the most important curricula related to society. Therefore, it is necessary to find special attention by those who are responsible for the process of finalizing the curricula. If this is done, education will have achieved its objectives through the outputs of learning the existence of a generation capable of carrying out its responsibilities. If any country experiences signs of weakness in its curricula, it would be quick to review and develop them. Hence, it is a means by which societies make the desired social changes and address their problems.

However, the purpose of this study is to identify the reality of gender in our Arabic language books for the first three grades in Jordan. In particular, the problem of the study is determined by answering the main question: "What is the reality of gender in our Arabic language books for the first three grades in Jordan?" Specifically, this study seeks to answer the following questions:

1. What is the reality of the gender in the committees of writing our Arabic language books for the first three basic grades and in supervising the composition and team review of the edition?

2. What is the reality of the repetition of gender-related words in our Arabic language books for the first three basic classes in Jordan?

3. What is the reality of the repetition of gender images in our Arabic language books for the first three grades in Jordan?

4. What is the reality of the repetition of gender-related titles in our Arabic language books for the first three basic classes in Jordan?

5. What are the gender roles which are included in our Arabic language books for the first three basic grades in Jordan?

\section{The Importance of the Study}

The importance of the study is shown by the importance of the language curriculum as a tool for communication between individuals, and it takes a large share of weekly classes. Also, the importance of the early stage of basic education has a significant impact on the social upbringing of the members of the society and on the impact on the values and trends of society. In addition, this study will serve as a feedback to educational leaders, and to those preparing curriculum and textbooks. This study also aims to supervise 
them as they show the reality of gender in our Arabic language books for the first three basic grades.

\section{The Terminology of the Study}

The study included the following terms:

Gender: This refers to the characteristics defined by society in regards to both women and men, including economic, social, political and cultural characteristics, as well as the roles and responsibilities men and women play in the society (Rubin \& Barrett, 2009).

Our Arabic language books for the first three basic grades include our Arabic language book for the first grade in its first and second parts, our Arabic language book for the second grade in the its first and second parts, and our Arabic language book for the third grade in its first and the second parts. Thus, this was decided upon by the Ministry of Education in Jordan to be taught in schools in Hashemite Kingdom of Jordan. This was after its approval starting from the academic year 2017/2018 based on the decision of the Council of Education No. (89/2016).

\section{Limitation of the Study}

The study includes the following limitations:

1. Content analysis is limited to our Arabic language books for the first three primary grades in the first and second parts as was defined in the study society.

2. The study is limited to the analysis of our Arabic language book for the first grade in its 14 lessons and training (Listen, repeat, write, memorize, write, memorize, memorize spilling, and dictate activities), and our Arabic language book for the second grade with its seventeen lessons and training (listen, talk, read, train, write, save, activity). Our Arabic language for the third grade is the basic lesson of the seventeen and the included exercises (listen, talk, read, exercises, write, dictate perspective, sing, activity).

\section{Methodology}

\section{The Study Approach}

The study makes use of the Content Analysis method.

\section{The Study Sample and Society}

The study community is represented by our Arabic language books for the first grade with its fourteen lessons and what its training includes. Our Arabic language book is for the second basic grade with its seventeen lessons and what the training includes. Hence, it also includes the Arabic language book for the third grade, with its seventeenth lesson, and the training included. The books, therefore, were fully analyzed. 


\section{The Study Tool}

In the preparation of the study tool - the tool of analysis - the previous studies that dealt with the subject of gender were examined in our Arabic language books. This includes the study of the Aga (2012), the study of Sarabi (2010), and the study of Naji and Rifa'i (2011). In addition, the lists of the proposed analysis were prepared. In order to verify the validity of the analysis tool, it was presented to 10 arbitrators who are specialized in curriculum and teaching methods. The arbitrators expressed their views regarding the appropriateness of the lists approved in this study. After an agreement of $80 \%$, the analysis tool was adopted finally.

\section{Analysis Procedures}

This study relies on the word, sentence, image, and idea as a unit of analysis. The category of analysis include: the gender of authorship committees, gender-specific precautions, gender images, and gender-specific titles. Gender roles were also included in this study tool (gender-related professions, creativity and innovation, social roles, health, national roles, heroism and courage), highlighting the role of males more than females and in regards to property ownership. After identifying the categories of analysis, and its units prepared based on the appropriate analysis of the tool, the form was used to collect data and to monitor the frequency of phenomena in the analyzed materials. Five formats were designed for data collection purposes: the first is for the authorship committees, the second for gender-related issues, the third for gender-related images, the fourth for lesson titles, and the fifth for gender roles (gender, creativity and innovation, social roles, health and national roles). Property ownership, heroism and courage are attributed to the role of males more than females.

After defining the categories, units, and forms of analysis, the process of analysis was initiated, reaching the results. The unit analysis process went through a series of careful steps. This starts by reading the words and sentences in our Arabic language books for the first three basic classes of exercises (hear, repeat, speak, write, read, spilling write, save, move dictation, and activities) for the first basic grade. This is followed by exercises (listen, talk, read, Memorize, activity) for the second basic class, and is lastly followed by exercises (listen, talk, read, exercises, type, dictate perspective, sing, activity) for the third grade. Thus, these words and sentences were analyzed and displayed on the analysis lists.

\section{Reliability Analysis}

The analysis was confirmed by the ratio of agreement among analysts. This is achieved through analysis and re-analysis of three lessons from our Arabic language books for the first three grades of basic education in Jordan 
(Chapter I and Chapter II) by the researcher. The analysis of the same lessons was carried out by another researcher after the clarification of the analysis tool. After then, it was calculated based on the proportion of agreement between the analysis using the method and equation (Auzzarouff \& Mayer, 1977). It also shows the proportion of agreement between the analyses made, and was calculated using the following equation:

Percentage of Agreement $=$ Number of agreed answers $/$ Number of agreed answers + Number of different answers X 100\%

The calculated coefficient of the first grade was $90 \%$, the second $92 \%$, and the third $88 \%$. Therefore, these ratios are appropriate for the purposes of this study.

\section{Statistical Processing}

To answer the study questions, we used repetitions and percentages.

\section{Results of the Study and Discussion}

What is the reality of gender in our Arabic language books for the first three grades in Jordan?

To answer this main question, the following sub-questions were answered.

\section{The Results of the First Question and its Discussion}

What is the reality of gender in the committees of writing Arabic language books for the first three basic grades and supervising the composition and team review of the edition?

To answer this question, the frequency and percentages of gender were extracted in the authorship, review, and review committees. This can be seen as shown in Table 1 below:

Table 1. Frequency and percentages of the committees of authorship, supervision and review

\begin{tabular}{|c|c|c|c|c|c|c|}
\hline \multirow[t]{2}{*}{ Grade } & \multirow{2}{*}{ Committee } & \multicolumn{2}{|c|}{ Male } & \multicolumn{2}{|c|}{ Female } & \multirow[t]{2}{*}{ Total } \\
\hline & & Number & Percentage & Number & Percentage & \\
\hline \multirow{3}{*}{$\begin{array}{l}\text { First } \\
\text { basic } \\
\text { grade }\end{array}$} & $\begin{array}{c}\text { Author of the } \\
\text { book }\end{array}$ & 1 & $16.17 \%$ & 5 & $83.33 \%$ & 6 \\
\hline & $\begin{array}{l}\text { Supervising } \\
\text { authorship }\end{array}$ & 3 & $100 \%$ & 0 & $0 \%$ & 3 \\
\hline & $\begin{array}{l}\text { Review } \\
\text { Edition } \\
\end{array}$ & 3 & $75 \%$ & 1 & $25 \%$ & 4 \\
\hline \multirow{4}{*}{$\begin{array}{c}\text { Second } \\
\text { basic } \\
\text { grade }\end{array}$} & $\begin{array}{l}\text { Author of the } \\
\text { book }\end{array}$ & 0 & $0 \%$ & 5 & $100 \%$ & 5 \\
\hline & $\begin{array}{l}\text { Supervising } \\
\text { authorship }\end{array}$ & 3 & $100 \%$ & 0 & $0 \%$ & 3 \\
\hline & $\begin{array}{l}\text { Review } \\
\text { Edition }\end{array}$ & 3 & $75 \%$ & 1 & $25 \%$ & 4 \\
\hline & $\begin{array}{l}\text { Author of the } \\
\text { book }\end{array}$ & 0 & $0 \%$ & 5 & $100 \%$ & 5 \\
\hline
\end{tabular}




\begin{tabular}{|l|c|c|c|c|c|c|}
\hline $\begin{array}{l}\text { Third } \\
\text { basic } \\
\text { grade }\end{array}$ & $\begin{array}{c}\text { Supervising } \\
\text { authorship }\end{array}$ & 3 & $100 \%$ & 0 & $0 \%$ & 3 \\
\cline { 2 - 7 } & $\begin{array}{c}\text { Review } \\
\text { Edition }\end{array}$ & 3 & $75 \%$ & 1 & $25 \%$ & 4 \\
\hline \multicolumn{2}{|c|}{ Total summation } & 19 & $51.35 \%$ & 18 & $48,65 \%$ & 37 \\
\hline
\end{tabular}

Table 1 shows that the Book Writing Committee for the first grade consisted of six members: five of them are females and one male. The percentage of females is $83.33 \%$ and that of males is $16.17 \%$. While it was composed of five members, all of them were females in the second and third primary school books (100\%). The team supervising the writing of Arabic language books for the first three basic grades may be three male members $(100 \%)$. The book review team consists of four members, three male and one female. The percentage of males is $75 \%$, while the proportion of females is $25 \%$. While there is a total recurrence of the total number of committees (37), 19 of them were males $(51.35 \%)$ while 18 were females $(48.65 \%)$.

Therefore, the previous figures reflect a clear increase in the number of female writers in the Arabic language textbooks for the first three basic grades, ranging from $83.33 \%$ to $100 \%$. This might be due to the fact that the majority of teachers in the basic grades are female. As a result, the ministry's direction was to be the authorship committee's females.

The results reflect a clear increase in the percentage of males based on the composition of supervising teams (100\% males) and the revision teams ( $75 \%$ males). This may be due to the gender gap in the society which still regards men to be more capable of administrative functions and supervision.

\section{Results Related to Answering and Discussing the Second Question} What is the reality of the repetition of words related to gender in our Arabic language books for the first three basic classes in Jordan?

In order to answer this question, the frequency and percentage of gender-specific words for each of our Arabic language classes were extracted for the first three basic grades. This is shown in Table 2 below:

Table 2. Frequency and percentages of gender-related vocabulary (male, female) in our

Arabic language books for the first three basic grades

\begin{tabular}{|c|c|c|c|c|c|c|}
\hline \multirow{2}{*}{ Grade } & \multicolumn{2}{|c|}{ Words related to males } & \multicolumn{2}{c|}{ Words related to females } & \multicolumn{2}{c|}{ The total } \\
\cline { 2 - 7 } & Repetition & Percentage & Repetition & Percentage & Repetition & Percentage \\
\hline $\begin{array}{c}\text { The first } \\
\text { basic }\end{array}$ & 264 & $64.08 \%$ & 148 & $35.92 \%$ & 412 & $100 \%$ \\
\hline $\begin{array}{c}\text { The } \\
\text { second } \\
\text { basic }\end{array}$ & 206 & $66.64 \%$ & 105 & $33.76 \%$ & 311 & $100 \%$ \\
\hline $\begin{array}{c}\text { The third } \\
\text { basic }\end{array}$ & 452 & $78.20 \%$ & 126 & $21.80 \%$ & 578 & $100 \%$ \\
\hline The total & 922 & $70.87 \%$ & 379 & $29.13 \%$ & 1301 & $100 \%$ \\
\hline
\end{tabular}


Table 2 shows the total number of repetitions of gender vocabulary (922), the total number of words $(70.87 \%)$, and the total frequency of genderrelated words (females) reached 379 and $29.13 \%$. It was noted from the previous table that male word frequency ratios increased from the first to second and to the third grades $(64.08 \%, 66.24 \%, 78.20 \%)$, repeatedly. However, these percentages have decreased for females from grade 1 to 2 to $3(35.92 \%, 33.76 \%, 21.80 \%)$, repeatedly.

The results reflect a clear bias among males based on the words used. This may be due to the fact that the society's view of gender is still more of a man's view of women than of women. This is evidenced by the fact that the committees of writing our Arabic language books were composed of females (up to 100\%). However, the apparent bias of males at the expense of females appeared in the lessons.

This may be attributed to the fact that most of the Arab media still present women in the traditional way, which led to the image of women being distorted by some media outlets. Nevertheless, women are seen to have adopted a negative image of themselves in order to conform to the picture drawn up in media.

It is interesting to note that there has been an increase in the number of words and images related to gender for female. Thus, the grades progress from the first row to the second and to the third. This may be due to the fact that the number of lessons in the first grade is 14 lessons (178 pages), the second grade is 17 lessons (185 pages), and the third grade is 17 lessons (190 pages). Therefore, the percentage of words and pictures is according to progress in grades.

\section{Results Related to Answering and Discussing the Third Question \\ What is the reality of the repetition of gender images in our Arabic language books for the first three grades in Jordan?}

To answer this question, the frequency and percentages of genderspecific images of each of our Arabic language classes were extracted for the first three basic grades. This can be seen in Table 3 below:

Table 3. Frequency and percentages of gender-related images (males, females) in our Arabic language books for the first three basic grades

\begin{tabular}{|c|c|c|c|c|c|c|}
\hline \multirow{2}{*}{ Grade } & \multicolumn{2}{|c|}{ Words related to males } & \multicolumn{2}{c|}{ Words related to females } & \multicolumn{2}{c|}{ The total } \\
\cline { 2 - 7 } & Repetition & Percentage & Repetition & Percentage & Repetition & Percentage \\
\hline $\begin{array}{c}\text { The first } \\
\text { basic }\end{array}$ & 47 & $54.65 \%$ & 39 & $45.45 \%$ & 86 & $100 \%$ \\
\hline $\begin{array}{c}\text { The } \\
\text { second } \\
\text { basic }\end{array}$ & 64 & $66.67 \%$ & 32 & $33.33 \%$ & 96 & $100 \%$ \\
\hline $\begin{array}{c}\text { The third } \\
\text { basic }\end{array}$ & 139 & $82.74 \%$ & 29 & $17.26 \%$ & 168 & $100 \%$ \\
\hline The total & 250 & $71.43 \%$ & 100 & $28.57 \%$ & 350 & $100 \%$ \\
\hline
\end{tabular}


Table 3 shows that the total number of repetitions of the images included in our Arabic language books for the first three basic grades related to gender reached 250 by $71.43 \%$ of the total number of pictures. The total frequency of gender-related images was 100 and $28.57 \%$ of the total number of pictures. It is noted from the previous table that the rates of recurrence of images related to males increased from the first row to the second and to the third $(54.65 \%, 66.67 \%, 82.74 \%)$, rankly. However, these percentages decreased for female images from grades 1 to 2 to $3(45.35 \%, 33.33 \%$, $17.26 \%$ ), rankly.

The increase in male-related images of female images may be due to the fact that most of the male book writers were male. The painters came for only three male books (First grade - second part, second grade - second part, second grade - first part), two male and a female books (third grade part one, part two), and three males and a female book (first row part I). This, therefore, reflected male attitudes on the drawings.

\section{Results Related to Answering and Discussing the Fourth Question What is the reality of the repetition of the titles of gender lessons in our Arabic language books for the first three grades in Jordan?}

To answer this question, the frequency and percentages of the gender headings of each of our Arabic language classes were extracted for the first three basic grades. This can be seen in Table 4 .

Table 4. Frequency and percentages of gender-related titles (males, females) in our Arabic language books for the first three basic grades

\begin{tabular}{|c|c|c|c|c|c|c|c|c|}
\hline Grade & \multicolumn{2}{|c|}{ Titles related to males } & \multicolumn{2}{c|}{ Titles related to females } & \multicolumn{2}{c|}{ General titles } & \multicolumn{2}{c|}{ The total } \\
\hline & Repetition & Percentage & Repetition & Percentage & Repetition & Percentage & Repetition & Percentage \\
\hline $\begin{array}{c}\text { First } \\
\text { basic }\end{array}$ & 1 & $7.14 \%$ & 0 & $0 \%$ & 13 & $92.86 \%$ & 14 & $100 \%$ \\
\hline $\begin{array}{c}\text { Second } \\
\text { basic }\end{array}$ & 3 & $17.65 \%$ & 1 & $5.88 \%$ & 13 & $76.47 \%$ & 17 & $100 \%$ \\
\hline $\begin{array}{c}\text { Third } \\
\text { basic }\end{array}$ & 4 & $23.53 \%$ & 1 & $5.88 \%$ & 12 & $70.59 \%$ & 17 & $100 \%$ \\
\hline Total & 8 & $16.67 \%$ & 2 & $4.17 \%$ & 38 & $79.16 \%$ & 48 & $100 \%$ \\
\hline
\end{tabular}

Table 4 shows that the total number of repetitions of the titles included in our Arabic language books for the first three basic grades related to gender reached 8 by $16.67 \%$ of the total number of titles. The total frequency of gender (female) titles was 2 and was $4.17 \%$ of the total number of titles. The total number of titles (38) was $79.16 \%$.

The increase in the ratio of male titles to the ratio of female genderrelated titles based on the control of community ideas may be attributed to the authors of the book. In addition, the teams supervise the authoring and review 
of male books. Also, it can play a significant role in selecting the titles of the lessons or modifying the titles that were put forward.

\section{Results Related to Answering and Discussing the Fifth Question What gender roles are included in our Arabic language books for the first three basic classes in Jordan?}

The ideas related to gender roles in our Arabic language books for the first three basic grades showed several indicators related to females and males. The following is a review:

\section{Gender-related Professions}

To identify gender-related occupations in our Arabic language books for the first three basic grades, the calculation of repetitions and percentages of occupations in the books was performed. However, this can be seen in Table 5 below.

Table 5. Frequency and percentages of occupations related to gender

\begin{tabular}{|c|c|c|c|c|c|}
\hline Occupation & Frequency & Percentage & Occupation & Frequency & Percentage \\
\hline Police man & 2 & $2.30 \%$ & Policewoman & 0 & $0 \%$ \\
\hline Officer & 2 & $2.30 \%$ & Officer female & 0 & $0 \%$ \\
\hline Carpenter & 4 & $4.60 \%$ & Female carpenter & 0 & $0 \%$ \\
\hline Engineer & 2 & $2.30 \%$ & Female engineer & 2 & $5.71 \%$ \\
\hline Teacher & 9 & $10.34 \%$ & Female teacher & 13 & $37.14 \%$ \\
\hline Trainer & 2 & $2.30 \%$ & Female trainer & 1 & $2.86 \%$ \\
\hline Solder & 2 & $2.30 \%$ & Female solder & 0 & $0 \%$ \\
\hline Painter & 2 & $2.30 \%$ & Female painter & 1 & $2.86 \%$ \\
\hline Farmer & 10 & $11.49 \%$ & Female farmer & 0 & $0 \%$ \\
\hline Pilot & 18 & $20.70 \%$ & Female pilot & 0 & $0 \%$ \\
\hline Hunter & 12 & $13.79 \%$ & Female hunter & 0 & $0 \%$ \\
\hline Nurse & 0 & $0 \%$ & Female nurse & 16 & $45.71 \%$ \\
\hline Exhibition owner & 1 & $1.15 \%$ & $\begin{array}{c}\text { Female } \\
\text { Exhibition owner }\end{array}$ & 0 & $0 \%$ \\
\hline Driver & 2 & $2.30 \%$ & Female driver & 0 & $0 \%$ \\
\hline Journalist & 1 & $1.15 \%$ & Female journalist & 0 & $0 \%$ \\
\hline Servant & 3 & $3.45 \%$ & Servant & 0 & $0 \%$ \\
\hline Physician & 5 & $5.75 \%$ & $\begin{array}{c}\text { Female } \\
\text { physician }\end{array}$ & 2 & 5.71 \\
\hline Dentist & 1 & $1.15 \%$ & Female dentist & 0 & $0 \%$ \\
\hline Ophthalmologist & 3 & $3.45 \%$ & $\begin{array}{c}\text { Female } \\
\text { ophthalmologist }\end{array}$ & 0 & $0 \%$ \\
\hline Worker & 4 & $4.60 \%$ & Female worker & 0 & $0 \%$ \\
\hline Sheep keeper & 2 & $2.30 \%$ & $\begin{array}{c}\text { Female sheep } \\
\text { keeper }\end{array}$ & 0 & $0 \%$ \\
\hline The total & 87 & $100 \%$ & The total & 35 & $100 \%$ \\
\hline
\end{tabular}

The sentences and words related to females in the books showed the occupations practiced by women (nurse, teacher, engineer, doctor, trainer, and painter), while the sentences and words relating to males in the books showed 
the occupations practiced by the men (pilot, hunter, farmer, teacher, doctor, worker, carpenter, servant, ophthalmologist, policeman, officer, engineer, trainer, soldier, painter, driver, journalist, dentist). It was noted from the above that female occupations were limited to six occupations with a frequency of 35, while the professions related to males were nineteen professions with a frequency of 87. The occupations (female teacher, engineer, doctor, trainer, painter, farmer) were common between males and females, whereas professions (pilot, hunter, worker, carpenter, Policeman, officer, soldier, driver, journalist, and dentist) were common among males. Thus, the nursing profession was limited to females. This reflects the bias of males at the expense of women, although the social reality of Jordanian women is contrary to the situation. In this case, women entered all areas of work equally with men together with women workers, police, pilots, dentists etc. This therefore states that the stereotype of female work still dominates the mentality of the authors of the curriculum and thus reflects the content of the book.

Subsequently, an example of this thesis is the fifth lesson in the first row in the field, which included the words "The Seed of My Mother, Wheat and Barley," "My Father's Land," and in the sixth lesson of the second grade, "I will be a pilot," "His father took him to the dentist." In this lesson, the role of males in agriculture, aviation, medicine and the neglects of the role of females were highlighted. This is despite the fact that the social reality in Jordan includes the effective participation of females in agricultural, aviation, and dental work.

This is in line with Brahmah's (2006) report that the school curriculum in Jordan, especially the Arabic language, not only reinforces the reactionary image of women in the curricula, but is also an Arab heritage that varies from country to country. He argued that the images of women in Arab curricula, especially in Jordan, were devoid of its real context and is confined to a very narrow framework. Women do not respond in many ways to basic classes in the form of decision makers. Repeatedly, he stated that the curriculum focuses on the role of women as the head of the family and almost restricts her role in the care of children and guidance and care of the house and in preparing food. This is in addition to the profession of teacher and nurse, which is frequent and more linked to women than men.

These results are consistent with the results of the Aga (2012) study, which showed less attention to the professional roles of contemporary women. Amini and Birandiji (2012) showed a bias towards women's jobs related to nursing and education.

\section{Creativity and Innovation}

To learn about the creativity and innovation related to gender in our Arabic language books for the first three basic grades, the calculation of 
repetitions and percentages of creativity and innovation were presented in the books. This can be seen in Table 6 .

Table 6 . The percentage of creativity and innovation related to gender

\begin{tabular}{|c|c|}
\hline The Creative Role & Frequency \\
\hline Thomas Edison & 1 \\
\hline Ibn battouta & 1 \\
\hline One of Muslims scientist & 1 \\
\hline Clever kid & 1 \\
\hline The little inventor & 1 \\
\hline Children thinkers & 1 \\
\hline The total & 6 \\
\hline
\end{tabular}

The sentences and words in our Arabic language books for the first three basic classes show that creativity and innovation are limited to males without females. An example of this is the 15th lesson in our second Arabic book which is Thomas Edison, the inventor of the light bulb. In the same lesson, the following was shown: "Search the World Wide Web for information ... about a world of Arab and Muslim scientists and its achievements." In the eighth lesson in the third grade, the following was shown "Ibn Battuta the greatest Muslim traveler." Finally, the tenth lesson states "the inventor of the small." This is in addition to the words and phrases such as "He was born intelligent, the inventor of the small, and the children of thinkers, and neglected the books of creative and creative women, both Arab and international."

Subsequently, the focus on males in issues related to thinking and creativity may be due to the fact that Arab societies focuses more on male models than on females, whether in Arab or Islamic history. This may play a negative role in the failure of women in their scientific and creative role to consolidate the textbooks of the concept of linking creativity and excellence in males. However, this deprives the society of female creations that may outweigh male creations.

These results are consistent with the results of the Sarabi (2010) study, which showed disregard for female creative works.

\section{Social Roles}

To learn about the social roles of gender in our Arabic language books for the first three basic grades, the calculation of frequencies and percentage of social roles in books was performed. This can be seen in Table 7 below: 
Table 7. Frequency and percentage of gender roles

\begin{tabular}{|c|c|c|c|c|c|}
\hline Social roles & Frequency & Percentage & Social roles & Frequency & Percentage \\
\hline Father & 16 & $41.03 \%$ & Mather & 7 & $63.63 \%$ \\
\hline Grandfather & 5 & $12.82 \%$ & Grandmother & 3 & $27.27 \%$ \\
\hline Uncle & 10 & $25.64 \%$ & Aunt & 1 & $9.09 \%$ \\
\hline Cousin & 1 & $2.56 \%$ & $\begin{array}{c}\text { Female } \\
\text { cousin }\end{array}$ & 0 & $0 \%$ \\
\hline Brother & 7 & $17.25 \%$ & Sister & 0 & $0 \%$ \\
\hline The total & 29 & $100 \%$ & The total & 11 & $100 \%$ \\
\hline
\end{tabular}

Table 7 shows the social roles of males (father, uncle, brother, grandfather, cousin) and females (mother, grandmother, aunt) came and were repeated (11). It was noted that the frequencies related to the social roles of males are higher than the frequencies related to the social roles of females. Therefore, this is consistent with the Jordanian social reality, which gives more social roles to males.

\section{Health}

To identify gender-related health roles in our Arabic language books for the first three primary grades, the frequency and percentage of health roles in the books was stated. Thus, this can be seen in Table 8 .

Table 8. Frequency and percentage of health roles related to gender

\begin{tabular}{|c|c|}
\hline The Health Role & The Frequency \\
\hline I wash my hand & 1 \\
\hline I wash my body & 1 \\
\hline $\begin{array}{c}\text { You, the student, need to take care of your } \\
\text { eyes }\end{array}$ & 1 \\
\hline I clean my teeth & 1 \\
\hline Zafer is a clean and tidy student & 1 \\
\hline He clean his teeth & 4 \\
\hline He wash his hands and face & 1 \\
\hline The total & 11 \\
\hline
\end{tabular}

Table 8 shows that health roles were limited to males without females. Therefore, the previous result is contrary to the social reality of Jordanian society, which refers to the care of women with health dimension. It also has to do with cleanliness, more than men, due to their role in maintaining the cleanliness of the house and in ensuring personal hygiene.

\section{National Roles}

To identify the national gender roles in our Arabic language books for the first three basic grades, we have calculated the frequency and percentage of national roles which are contained in the books. Thus, this can be seen in Table 9 below. 
Table 9. Frequency and percentage of national gender roles

\begin{tabular}{|c|c|}
\hline The Role & The Frequency \\
\hline He Celebrate the independent day & 1 \\
\hline He Rise up the flags & 1 \\
\hline $\begin{array}{c}\text { He said what is the most beautiful } \\
\text { flag }\end{array}$ & 1 \\
\hline She said my flag is proud & 1 \\
\hline Samer raises the flag of our country & 1 \\
\hline The decorate courtyard & 1 \\
\hline The total & 6 \\
\hline
\end{tabular}

Table 9 shows that national roles can be seen predominantly in both males and females. In addition, there is only one role for females in this area. The recurrence of the above table shows that 5 recurrences out of 6 dealt with the national roles of males.

This may be attributed to the concentration of society and its institutions on the national dimensions of males more than females. Also, there is an emergence of male image in national celebrations more than female, if they are carrying the national flag or raising the flag.

These results correspond to the results of the Aga (2012) study, which showed that the attention to the national roles of women was less than that of males.

\section{Championship and Courage}

The sentences and words in our Arabic language books for the first three primary grades show that the championship and the courage are limited to males compared to females. An example of this is the fifteenth lesson in our Arabic language book for the third grade titled "Essa Al Awam." Thus, this speaks of the heroism of this man who was swimming at night to deliver messages to the army, but died in the course of swimming. The books neglected women's tournaments that abound in Arab, Islamic and world history. This might occur due to the stereotypes of men and women that show that men perform heroic acts and protect women from exposure to dangers. This picture can be seen in the media such as in television, cinema, and literary novels. Hence, this shows the man's heroic appearance (Super Man) and, perhaps, this image dominates the minds of the developers of the curriculum.

Furthermore, the results of this study are consistent with the findings of Jackie and Collins (2010), which show that great and noble work is attributed to men. The results of the Sarabi (2010) study showed disregard for the heroic roles of women. 


\section{Highlight the Role of Males More than Females}

The sentences and words of some lessons highlight the role of males more than the role of females, while the same pictures show that the number of females is more than that of males. Examples of that second lesson, Madrasati, includes the following sentences: "My school is my second home." Basem said: "In my school, I read, write and learn everything new. I love my school, respect my teacher, and cooperate with my friends: Hazem, Rami and Sami." However, it should be noted that based on the previous sentences, the focus is on the male student (Basim) and he considers his school to be his second home. They learn where to read and write, and all of them knew how to show love and respect for the teacher, and how they can cooperate with male friends (Hazem, Rami and Sami). This sentence contrasts clearly with the pictures that were presented in the same lesson. As he stated: "my second Betty school." The picture of the row included Taliben males and eight female students. Three students sat together at a table, while five students sat at another table. The third picture, which included three male students and four female students, shows them sitting on the ground while drawing. Just as the pictures show that the female students in the row are more than the number of males, in the same way the sentences focused on males except for the parameter.

This is in addition to the fourth lesson "cleanliness," which included the following sentences: "I Tamer keep my cleanliness, wash my body with soap and water, clean my teeth brushing and paste, wash my hands before eating and after." The pictures show Tamer washing his body with soap and water, brushing his teeth, and washing his hands. It appears in this study that the cleanliness of the Tamer (male) is limited, and does not address any female in the subject. This is based on the fact that cleanliness is not limited to males without females. However, this is a participatory process in our society, which can be handled by women more than men.

The above may be attributed to the prevailing social outlook in the society. This depends on males and their emphasis on females, given that women are weak and need male care, and that men have control over the family.

These findings are consistent with the findings of Jackie and Collins (2010), which show women's association with traditional roles. Thus, their appearance is characterized by weaker personality traits and more negative personality than men.

\section{Ownership}

The sentences and words in the books show that the property is for males without females. Perhaps, it is regarded as the most prominent example of the third lesson "Dar Jedi." The text shows that the ownership of the house 
of the grandfather, and the lesson of the eleventh "smart phone" was the words "owner of the exhibition." Thus, this shows that the "ownership of the exhibition" of a man, "gold and dust" in the second lesson, and the word "that the brothers wanted to share the wealth of their father after his death" appears that the inheritance is shared by the males. This may be due to the stereotypes of some members of the society that deprive women of their right to inheritance and property. Nevertheless, there is a change in this image based on the principle of male-female partnership in regards to property or property rights for females. Thus, this is regarded now as a feature of social life in Jordan, especially after the exit of women to work. Also, it is accompanied by those involved in the purchase of land and construction thereon. This is in addition to the right of women in inheritance and has been guaranteed by legal legislation.

\section{Conclusion}

Based on the results of the study, the following conclusions can be drawn:

1. The majority of the committee for the writing of Arabic language books for the first three basic classes was female. The supervision team for writing Arabic language books for the first three basic grades might be male only, while the book review team consists of four members, three of whom are male and one female. The total number of committees was 37, which constitutes 19 males by $51.35 \%$ and 18 females by $48.65 \%$.

2. The total number of repetitions of the gender vocabulary in our Arabic language books for the first three basic grades was 922 (70.87\%) based on the total number of words, and the total frequency of gender-related words was $379(29.13 \%)$.

3. The total number of repetitions of the images included in our Arabic language books for the first three basic grades in terms of gender (males) reached 250 by $71.43 \%$ based on the total number of pictures, and the total frequency of gender images (females) $(28.57 \%$ ) based on the total number of photographs.

4. The total number of repetitions of the titles included in our Arabic language books for the first three basic grades on gender was 8 with $16.67 \%$ of the total number of titles, and the total frequency of gender references (2) $(4.17 \%)$ of the total number of titles. The total number of titles (38) was $79.16 \%$ based on the total number of addresses.

5. The analysis of the gender roles in our Arabic language books for the first three basic grades showed:

- The occupations practiced by women (nurse, teacher, engineer, doctor, trainer, and painter), while the sentences and words related to males in the books showed the occupations practiced by men (pilot, hunter, farmer, 
teacher, doctor, worker, carpenter, A policeman, an officer, an engineer, a trainer, a soldier, a painter, a driver, a journalist and a dentist).

- Creativity and innovation is limited to males without females.

- The social roles of the males were father, uncle, brother, grandfather and cousin, while the females include mother, grandmother, and aunt.

- Health roles were limited to males without females.

- National roles are mostly for male compared to females.

- Championship and courage are limited to males without females.

- There is an emergence of the role of males more than the role of females, while the pictures of the same lessons show that the number of females were more.

- Ownership of males without females.

\section{Recommendations}

In the light of the results, the study recommends the following:

- To enrich the books and their lessons in gender roles in a balanced manner that ensures the participation of both sexes in these roles and which is in line with the social reality of these roles.

- The development of a matrix of gender roles representing the social reality in Jordan trends to be modified in the area of gender and the commitment of authors of textbooks.

- Pay attention to gender roles that have not received enough repetitions and enrichment, especially with regard to the roles and image of women.

- Modify the image of the woman in school textbooks in line with the development of the social reality of Jordanian society, which is the legislation that guarantees women the rights to education, jobs, and ownership of property.

\section{References:}

1. Agha Sana (2012). The Image of Women in Arabic Language Books in the Upper Elementary Stage in Palestine. An Analytical Study, Unpublished, Master Thesis, Al-Azhar University, Gaza.

2. Al-Jarbawi Tifidah \& Al-Saafeen Nasser (2004). Gender in Palestinian textbooks. Future Journal of Arab Education, Arab Center for Education and Development - Egypt, Issue 34.

3. Al-Maamari Khawla (2009). The image of women in the books of social studies of the classes Basic Education in the Sultanate of Oman, Master's thesis unpublished, Amman: College of Education Sultan Qaboos University.

4. Al-Sarabi Siham (2010). The Image of Women of the University of Damascus Journal, Volume 26, No. (2+1, pp. 463-496). 
5. Al-Spalk Ahmed Mansour (2004). Anam al-Ilam in the statement of the issue of women in Islam, first edition, Dar al-Redha for publication and distribution, Giza, Egypt.

6. Al-Tartir Montaha, Al-Qarabawi Samar, Smadi Ahlam, Aweida Samah, \& Salama Zakya (2017). Our Arabic Language Second Grade, Part One, Ministry of Education, Jordan.

7. Arma Al-Samadi, Ghada Gad, Asma Al-Tarawneh, \& Siham (2017). Arabic Language, Third Grade, Part II, Ministry of Education, Jordan.

8. Asali Alia (2005). Image of Women in the Civic Education Curriculum for Grade 1 through Grade 6, Ram Center for Studies and Human Rights, available at www.rchrs.org

9. Amini, M. \& Birandji, P. (2012). Gender Bias in The Iranian High School EFL Textbooks, English Language Teaching, Vol. 5, No. 2. pp. $134-147$.

10. Apple, M.W. (1995). Ideology and Curriculum, Routledge, New York, USA.

11. Azaroff, B. \& Mayer, B. (1977). Applying behavior analysis procedures with children and youth. New York: Holt, Rinehart \& Winston.

12. Barhoumah Musa (2006). The image of women in the Jordanian school curriculum: Baba reads in the salon and Mama prepares the soup in the kitchen, the future, number 2222, Tuesday 28/3/2006, available

on:

http: // www.almustaqbal.com/storiesv4.aspx? Storyid-1720971

13. Dakhil Hussein (2016). Social networking and its role in drawing the image of women from the perspective of Jordanian university students, unpublished, master thesis, Middle East University.

14. Gamal Magda, Zu'bi Nidal, Maaytah Sumaya, Kmarkji Mays, \& Hamida Dima (2017). Our Arabic Language First Grade, Part 1, Ministry of Education and Learning Jordan.

15. Hammadneh Adeeb \& Al-Moghid Omar (2011). Islamic Values in the Arabic Language Books for the First and Second Levels of Basic Education in Jordan, Journal of the Islamic University, Humanities Series, Vol 19, No. 1, pp. 487 - 517.

16. Hashem Soraya \& Mansour Najah (2012). Training Manual for Trainers and Trainers on Gender Issues in Education, Educational Center for Research and Developme;nt, United Nations Educational, Scientific and Cultural Organization.

17. Jackie, F.K. \& Collins, P. (2010). Construction of Gender: A Comparison of Australian and Hong Kong English Language Textbooks, Journal of Gender Studies, Vol. 19, No. 2, pp. 121- 137. 
18. Kurshid, K., Gilani, I., Ali, S., \& Hashmi Muhammad (2010). A Study of The Representation of Female Image In The Textbook of English and Urdu at Secondary School Level, Pakistan Journal of Social Science, Vol. 30, No.2. pp. 425-437

19. Morise, K. \& Margaret, P. (ED) (1972). The Challenge of Change, NFER Publishing Company

20. Naji \& Rifa'i (2011). The image of women in the books of Arabic language and social materials in primary and intermediate education in the Kingdom of Saudi ,Arabia Journal of the University of Damascus, volume (first issue + second), pp. 405 - p.

21. Rejabi Imad (2015). Palestinian curriculum distinguishing between men and women|\Palestine, lavailablelat http://palestine.assafir.com/Article.aspx?ArticleID=3174 Retrieved on 11/9/2017.

22. Rubin, D. \& Barrett, N. K. (2009). Gate Workshop Materials: Integrating Gender in Agricultural Value Chains (INGIA-VC) in Tanzania. Report prepared for Development and Training Services, Inc. (dTS).

23. Shteiwi Moussa \& Dagestani Amal (1994). Jordanian Women and Political Participation, Center for Strategic Studies, University of Jordan, Amman, Jordan.

24. The Global Gender Gap Report (2016) The World Economic Forum, http://reports.weforum.org/global-gender-gap-report-2016/

25. United Nations Development Fund for Women (UNIFEM), West Asia Office (1999), Gender and Development Detector, Reference Bag, Amman, Jordan.

26. Yang Chi (2014). Gender Stereotyping and Gender Discourse in a Hong Kong Primary English Textbook Series. Virtual Library, Thesis submitted for the Degree of Doctor of Philosophy Retrieved from (www.biblotecavirtualut.sugam.edu). 